\title{
Numerical simulation of particle motion at cucumber straw grinding process based on EDEM
}

\author{
Yunfeng $\mathrm{Xu}^{1,2,3}$, Xiliang Zhang ${ }^{3 *}$, Shuo $\mathrm{Wu}^{4}$, Cheng Chen ${ }^{3}$, Jizhang Wang ${ }^{4}$, Shouqi Yuan ${ }^{1}$, \\ Bin Chen ${ }^{2}$, Pingping $\mathrm{Li}^{4,5}$, Rongjun $\mathrm{Xu}^{2}$ \\ (1. National Research Center of Pumps, Jiangsu University, Zhenjiang 212013, Jiangsu, China; \\ 2. Lanshen Group Co., Ltd., Nanjing 211500, China; \\ 3. School of Mechanical Engineering, Jiangsu University, Zhenjiang 212013, Jiangsu, China; \\ 4. Key Laboratory of Modern Agricultural Equipment and Technology, Ministry of Education and Jiangsu Province, \\ Jiangsu University, Zhenjiang 212013, Jiangsu, China; \\ 5. College of Biology and Environment, Nanjing Forestry University, Nanjing 210037, China)
}

\begin{abstract}
Simulation of straw grinding process based on discrete element method (DEM) was proposed. According to the force analysis and kinematics analysis, the differential equation of straw particle motion on hammers was deduced, and the formation mechanism of the material circulation layer was obtained. Geometric model of grinder, particle model and contact model were established by EDEM software. The influence of hammer number, hammer thickness and gap of the hammer-sieve on particle grinding number and power consumption were obtained by single factor simulation test. The grinding process is divided into three stages. The hammer smashing plays a dominant role in $0-0.25 \mathrm{~s}$. While the hammer smashing particle number increases slowly and then decreases to the lowest level in $0.25-0.60 \mathrm{~s}$, the tooth plate smashing particle number increases rapidly and dominates, and then forming a material circulation layer. The hammer and tooth plate smashing particle number is basically stable in 0.60-2.00 s, and the tooth plate smashing occupies the dominant position. With the increase of the number and thickness of hammers, the power consumption of crusher tends to increase, and with the increase of the gap between hammers and sieves, the power consumption of crusher decreases first and then increases. The results can provide guidance for the development of high-efficiency and energy-saving grinding equipment for cucumber straw.
\end{abstract}

Keywords: cucumber straw, grinding process, particle motion, numerical simulation, EDEM

DOI: $10.25165 /$ j.ijabe.20201306.5452

Citation: Xu Y F, Zhang X L, Wu S, Chen C, Wang J Z, Yuan S Q, et al. Numerical simulation of particle motion at cucumber straw grinding process based on EDEM. Int J Agric \& Biol Eng, 2020; 13(6): 227-235.

\section{Introduction}

Cucumber is one of the ten most popular vegetable crops in the world because of its high yield, good benefit, convenient eating and rich nutrition ${ }^{[1,2]}$. With the adjustment of dietary structure and the rapid development of protected horticulture in China, the cucumber planting area has expanded rapidly, and cucumber production has been achieved throughout the year ${ }^{[3,4]}$. Since the 1970s, the cucumber planting area and yield in China have ranked first in the world. At present, the cucumber yield in China accounts for more

\section{Received date: 2019-10-11 Accepted date: 2020-03-30}

Biographies: Yunfeng Xu, PhD, research interests: agricultural and mechanical engineering, Email: xuyunfeng@ujs.edu.cn; Shuo Wu, Master, research interests: agricultural engineering, Email: 2875514410@qq.com; Cheng Chen, Master, research interests: mechanical engineering, Email: 744003890@qq.com; Jizhang Wang, PhD, Associate Professor, research interests: agricultural and biological engineering, Email: whxh@ujs.edu.cn; Shouqi Yuan, PhD, Professor, research interests: fluid machinery and engineering, Email: shouqiy@ujs.edu.cn; Bin Chen, PhD, Professor, research interests: fluid machinery and engineering, Email: chenbin21cn@126.com; Pingping Li, PhD, Professor, research interests: agricultural engineering, Email: lipingping@ujs.edu.cn; Rongjun $\mathbf{X u}$, Engineer, research interests: fluid machinery and engineering, Email: 616058400@qq.com.

*Corresponding author: Xiliang Zhang, PhD, Professor, research interests: agricultural engineering. School of Mechanical Engineering, Jiangsu University, Zhenjiang 212013, Jiangsu, China. Tel: +86-13815179339, Email: zhangxl@ ujs.edu.cn. than $70 \%$ of the world's ${ }^{[5-7]}$. Large-scale cucumber cultivation puts forward new requirements for the disposal and utilization of cucumber straw. Cucumber straw has the characteristics of high moisture content, strong ductility, large volume and rich nutrient content. It is not convenient for long storage, transportation and processing. There is almost no comprehensive utilization of cucumber straw. Cucumber straw waste is discarded randomly in fields, roadsides and river ditches, which not only wastes valuable resources, but causes a large area of agricultural pollution ${ }^{[8-11]}$. Ngamnikom et al. ${ }^{[12]}$ considered that grinding efficiency and energy consumption played an important role in the comprehensive utilization of straw. Bitra et al. ${ }^{[13]}$ proposed that the energy consumption of crusher accounts for $1 / 3-2 / 3$ of the total energy consumption of feed industry. Therefore, how to achieve high efficiency and low energy consumption grinding process is an urgent problem to be solved.

Hammer mill is widely used in the pretreatment of crop straw because of its good versatility, convenient operation and reliable performance ${ }^{[14,15]}$. However, owing to the existence of the material circulation layer, the traditional hammer mill has obvious shortcomings such as high energy consumption, low efficiency, serious dust in the working environment, and high noise ${ }^{[16]}$. Traditional methods of agricultural machinery research are mainly based on theoretical analysis and experimental research, but the test method has a long cycle and high cost. With the rapid development of computer technology, the numerical simulation 
method has been introduced into the field of agricultural machinery and equipment research and development due to its advantages of low cost, good operation and high efficiency ${ }^{[17,18]}$. McCarthy et al. ${ }^{[19]}$ used discrete element method (DEM) to simulate the mixing of particles in rotating drum. Sakaguchi et al. ${ }^{[20]}$ used the DEM to simulate the vibration separation process of rice and brown rice, and compared the simulation results with the experimental results. $\mathrm{Wu}$ et al. ${ }^{[21]}$ studied the vertical helical mixing mechanism of tomato straw crumbs by the DEM. The above researches mainly involve the mixing and cleaning of particles, and the particles do not change. Crushing involves the process of particle size change from large to small ${ }^{[22,23]}$. In order to develop high efficient and energy-saving crushing machinery and equipment for cucumber straw, the theoretical analysis and the DEM are used to simulate the crushing process of cucumber straw, and explore the optimal crushing process parameters to improve the crushing efficiency and reduce the power consumption per ton of material. It will help to solve the non-point source pollution of agricultural crops such as cucumber straw. It is of great significance to promote the comprehensive utilization of straw resources and to construct efficient ecological recycling agriculture.

\section{Motion analysis of straw particles on hammer}

When the cucumber straw enters the grinding chamber of the hammer mill, it is eccentrically struck by the hammer hinged on the high-speed rotating rotor. Assuming that the straw particles are spherical, ignoring the rotating speed of the air swirl generated by the high-speed rotating rotor ${ }^{[24]}$, the force of the straw particles on the hammer is shown in Figure 1.

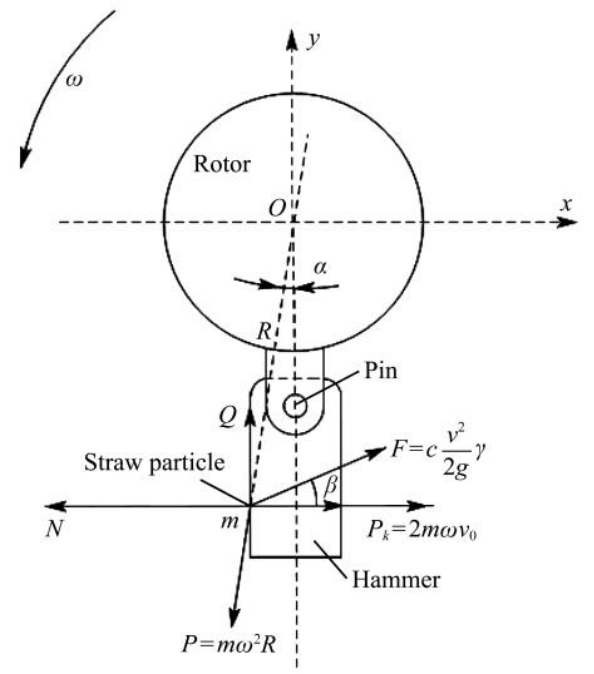

Figure 1 Force analysis of the particle on the hammer

When the particles move on the hammer, they are subjected to the centrifugal force, the airflow pressure, the Coriolis force, the friction with the hammer, the reaction force of the hammer and gravity. According to Newton's second law of motion, it can be obtained that:

$$
m a=\sum F=P+F+P_{k}+Q+N+G
$$

where, $m$ is the mass of straw particles, $\mathrm{kg}$; $a$ is the instantaneous acceleration, $\mathrm{m} / \mathrm{s}^{2} ; P$ is the centrifugal force $(\mathrm{N}), P=m \omega^{2} R ; \omega$ is the angular velocity of the rotor, $\mathrm{rad} / \mathrm{s} ; R$ is the distance from the particle to the center of the rotor, $\mathrm{m} ; F$ is the air pressure $(\mathrm{Pa})$, $F=c \frac{v^{2}}{2 g} \gamma ; c$ is the constant; $v$ is the absolute velocity of the particle, $\mathrm{m} / \mathrm{s} ; \gamma$ is the air specific gravity; $P_{k}$ is the Coriolis force
(N), $P_{k}=2 m \omega v_{0} ; v_{0}$ is the relative velocity of the particle and the hammer, $\mathrm{m} / \mathrm{s} ; Q$ is the friction between the particle and the hammer (N), $Q=N f ; f$ is the friction coefficient; $N$ is the reaction force of hammer $(\mathrm{N}) ; G$ is gravity $(\mathrm{N}), G=m g$, because the particle mass is small, gravity can be ignored.

Particle motion is divided into rotational motion with hammers and relative sliding on hammers. For the time when the straw particles are stressed in Figure 1, they are decomposed in the radial and horizontal directions respectively, and it can be given that:

In radial direction

$$
m a=P \cos \alpha-Q-F \sin \beta
$$

In horizontal direction

$$
N+P \sin \alpha=P_{\mathrm{k}}+F \cos \beta
$$

Therefore, the differential equation of particle motion can be expressed as:

In radial direction

$$
m \frac{\mathrm{d} v_{0}}{\mathrm{~d} t}=m \omega^{2} R \cos \alpha-N f-c \frac{v^{2}}{2 g} \gamma \sin \beta
$$

In horizontal direction

$$
0=N+m \omega^{2} R \sin \alpha-2 m \omega v_{0}-c \frac{v^{2}}{2 g} \gamma \cos \beta
$$

Substituting Equation (3) into Equation (2), it can be obtained that

$$
\begin{aligned}
m \frac{\mathrm{d} v_{0}}{\mathrm{~d} t}= & m \omega^{2} R \cos \alpha-\left(2 m \omega v_{0}+c \frac{v^{2}}{2 g} \gamma \cos \beta\right. \\
& \left.-m \omega^{2} R \sin \alpha\right) f-c \frac{v^{2}}{2 g} \gamma \sin \beta
\end{aligned}
$$

The absolute velocity can be expressed as the sum of the relative velocity and the involved velocity, namely

$$
v^{2}=(\omega R)^{2}+v_{0}^{2}=(\omega R)^{2}+\left(\frac{\mathrm{d} y}{\mathrm{~d} t}\right)^{2}
$$

Dividing both sides of Equation (4) by $m$, it can be obtained that

$$
\begin{aligned}
y^{\prime \prime}= & \omega^{2} R(\cos \alpha+f \sin \alpha)-2 f \omega y^{\prime} \\
& -c \frac{(\omega R)^{2}+y^{\prime 2}}{2 m g} \gamma(f \cos \beta+\sin \beta)
\end{aligned}
$$

Equation (5) is the differential equation of motion of particles on hammers.

From the differential equation of motion of straw particles, it can be seen that the larger the particle is, the faster the moving speed on the hammer surface and the faster the falling speed on the material layer. Therefore, the large particle is in the outer material layer, while the small particle is slowly rotating at the inner material layer. The material circulation layer is formed, and the large particle is blocked on the sieve hole, while the small particle is easier to be hit by the hammer.

\section{Discrete element method}

The spatiotemporal multi-scale structure is one of the most important and difficult problems in the study of material crushing process. It is still very difficult to study the material crushing process from the perspective of experiment and theory. As a powerful numerical calculation method, discrete element method (DEM) can be used to analyze and solve the dynamic problems of material system, to simulate particle flow in particle system and powder, and to analyze the shear effect and filling characteristics of particles ${ }^{[25,26]}$. Material crushing also involves the temporal and spatial scale changes of particles. In this paper, the discrete 
particle model not only considers the flow characteristics of the fluid, but also the influence of particles on the flow of the fluid and the interaction between particles, which can better describe the time average behavior characteristics of the non-uniform flow structure in the particle fluid two-phase flow. EDEM software is the first CAE software based on modern discrete element model to simulate and analyze the behavior of particle system in industrial production. Users can directly import the solid model established by mainstream software such as CAD into EDEM to reflect the actual shape of particles, which greatly improves the accuracy of simulation. Furthermore, EDEM particle model can add force, material properties and physical properties parameters ${ }^{[27,28]}$. Combined with the mainstream CAE software, EDEM can also simulate the coupling of particle system with electromagnetic field and fluid ${ }^{[29-31]}$. With powerful post-processing tools, EDEM can visualize and graphically manipulate any combination of variables. The interface is clean, and the calculation is accurate and convenient.

\section{Simulation model}

\subsection{Geometric model of the mill}

The three-dimensional model of 3FC-500 hammer mill as shown in Figure 2 is established by Inventor software. The simulation device consists of rotor, hammer group, breaker plate and screen. The gas-solid two-phase flow of particles in milling chamber is also considered.

The parameters of the main components of the straw mill are shown in Table 1.

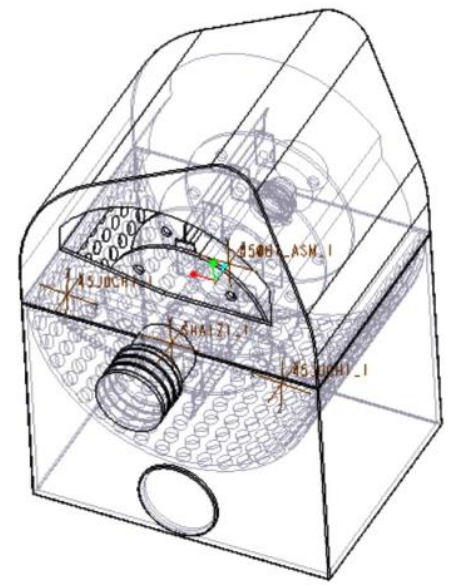

Figure 2 3D model of 3FC-500 straw hammer mill

Table 1 Description table of structure size

\begin{tabular}{clc}
\hline Part name & \multicolumn{1}{c}{ Parameter } & Value \\
\hline \multirow{2}{*}{ Rotor } & Diameter $D / \mathrm{mm}$ & 500 \\
& Length $L / \mathrm{mm}$ & 500 \\
& Rotational speed $/ \mathrm{m}^{-1} \mathrm{~s}^{-1}$ & $26,39,52$ \\
\hline \multirow{2}{*}{ Hammer group } & Thickness $h / \mathrm{mm}$ & $4,5,6$ \\
& Long $\times$ wide $\times$ aperture $/ \mathrm{mm}$ & $180 \times 50 \times 20.5$ \\
& number & $16,24,32$ \\
\hline \multirow{2}{*}{ Breaker plate } & Material & cast iron \\
& Shape & herringbone \\
\hline \multirow{2}{*}{ Sieve } & Size/mm & $4,8,12$ \\
& Material & stainless steel \\
\hline
\end{tabular}

\subsection{Particle model}

In particles of EDEM software model building module, the particle model of cucumber straw was established. The cucumber straw is approximated to a cylindrical shape after simplification, and the material particles are composed of several spherical particle units. The three-dimensional model is shown in Figure 3. When feeding, the radius of cucumber straw is $3 \mathrm{~mm}$, the length is $6 \mathrm{~mm}$, $9 \mathrm{~mm}$ and $18 \mathrm{~mm}$, respectively. According to the experiment, under the same rotating speed and time, cucumber straw with different moisture contents was sampled and graded by vibrating screen under different sieve apertures. The results are shown in Table 2. Particles larger than $6 \mathrm{~mm}$ can be ignored. After crushing, the radius of straw particles is $0.5 \mathrm{~mm}$, and the length is 1 $\mathrm{mm}, 3 \mathrm{~mm}$ and $6 \mathrm{~mm}$. According to the results of $\mathrm{Hu}$ et al ${ }^{[25]}$ and the mechanical properties test of cucumber $\operatorname{straw}^{[27,28]}$, the mechanical parameters of the particle model are shown in Tables 3 and 4 , respectively.

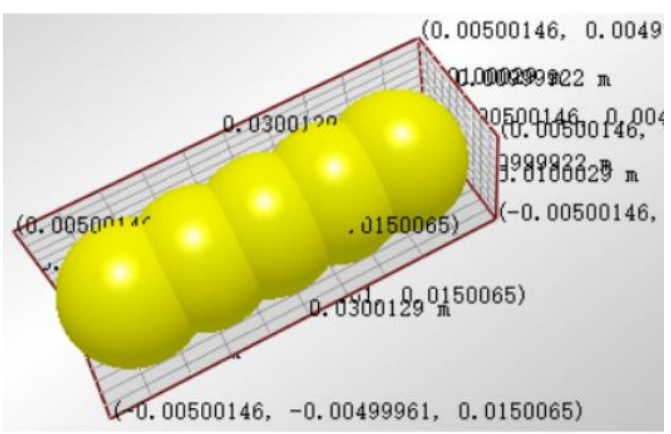

Figure 3 3D model of particle

Table 2 Particle size distribution of cucumber straw with different water contents after different sieve holes

\begin{tabular}{|c|c|c|c|c|c|c|c|c|}
\hline \multirow{2}{*}{$\begin{array}{l}\text { Sieve } \\
\text { pore } \\
/ \mathrm{mm}\end{array}$} & \multirow{2}{*}{$\begin{array}{l}\text { Time } \\
\text { /min }\end{array}$} & \multirow{2}{*}{$\begin{array}{l}\text { Consumption } \\
\quad / \mathrm{kW} \cdot \mathrm{h}\end{array}$} & \multirow{2}{*}{$\begin{array}{c}\text { Moisture } \\
\text { content } \\
1 \%\end{array}$} & \multicolumn{5}{|c|}{ Percentage of particle size/\% } \\
\hline & & & & $\begin{array}{c}0- \\
0.5\end{array}$ & $\begin{array}{c}0.5- \\
1.0\end{array}$ & $\begin{array}{l}1.0- \\
2.0\end{array}$ & $\begin{array}{c}2.0- \\
6.0\end{array}$ & $>6.0 \mathrm{~mm}$ \\
\hline 4 & 20 & 3.7 & 44 & 24.05 & 37.43 & 19.77 & 18.45 & 0.30 \\
\hline 16 & 20 & 3.7 & 20 & 69.53 & 26.01 & 3.42 & 0.81 & 0.23 \\
\hline 16 & 20 & 3.7 & 32 & 50.03 & 30.04 & 13.69 & 3.66 & 2.58 \\
\hline
\end{tabular}

Table 3 Parameters of simulation materials force properties

\begin{tabular}{clc}
\hline Type & \multicolumn{1}{c}{ Parameters } & Data \\
\hline \multirow{3}{*}{ Short straw } & Poisson ratio & 0.25 \\
& Shear modulus $/ \mathrm{Pa}$ & $7.95 \times 10^{4}$ \\
& Density $/ \mathrm{kg} \cdot \mathrm{m}^{-3}$ & 450 \\
\hline \multirow{2}{*}{ Long straw } & Poisson ratio & 0.25 \\
& Shear modulus $/ \mathrm{Pa}$ & $7.95 \times 10^{4}$ \\
& Density $/ \mathrm{kg} \cdot \mathrm{m}^{-3}$ & 150 \\
\hline \multirow{2}{*}{ Stainless steel } & Poisson ratio & 0.30 \\
& Shear modulus $/ \mathrm{Pa}$ & $8.1 \times 10^{8}$ \\
& Density $/ \mathrm{kg} \cdot \mathrm{m}^{-3}$ & 7850 \\
\hline
\end{tabular}

Table 4 Parameters of simulation materials interaction properties

\begin{tabular}{cll}
\hline \multicolumn{1}{c}{ Type } & Mechanical parameters & Data \\
\hline \multirow{3}{*}{ Short straw-short straw } & Restitution coefficient & 0.50 \\
& Static friction coefficient & 0.75 \\
& Rolling friction coefficient & 0.01 \\
\hline \multirow{3}{*}{ Short straw-long straw } & Restitution coefficient & 0.50 \\
& Static friction coefficient & 0.75 \\
& Rolling friction coefficient & 0.01 \\
\hline \multirow{3}{*}{ Long straw-long straw } & Restitution coefficient & 0.50 \\
& Static friction coefficient & 0.75 \\
& Rolling friction coefficient & 0.01 \\
\hline \multirow{3}{*}{ Stainless steel-short straw } & Restitution coefficient & 0.10 \\
& Static friction coefficient & 0.45 \\
& Rolling friction coefficient & 0.01 \\
\hline \multirow{2}{*}{ Stainless steel-long straw } & Restitution coefficient & 0.10 \\
& Static friction coefficient & 0.45 \\
& Rolling friction coefficient & 0.01 \\
\hline
\end{tabular}




\subsection{Contact model}

Due to the cylindrical straw particles will be replaced by small spherical particles, Hertz-Mindlin with bonding model is selected for both Particle to Particle and Article to Geometry contact models. The parameters of the bonding model are set according to the mechanical test results, as shown in Figure 4a. Particle Body Force uses the particle replacement model, as shown in Figure $4 \mathrm{~b}$. The rapid rotation of hammer group and the action of fan make the straw collision in the grinding chamber belong to the collision between large particles based on gas-solid two-phase flow. The stochastic collision model can be established by using gas dynamics and Boltzmann transport equation.

\begin{tabular}{|c|c|c|}
\hline E Parallel Bond Configuration & & $8 \quad 28$ \\
\hline $\begin{array}{l}\text { Formation } \\
\text { Start Time: } 0.095 \mathrm{~s}\end{array}$ & $\hat{i}$ & \\
\hline \multicolumn{3}{|l|}{ Active Bonds } \\
\hline Fraction + Fraction & $\begin{array}{l}\text { Hormal Stiffness per unit area: } \\
\text { Shear Stiffness per unit area: } \\
\text { Critical Normal Stress: } \\
\text { Critical Shear Stress: } \\
\text { Bonded Disk Radius: }\end{array}$ & \begin{tabular}{l|l|}
$6 e+09 \mathrm{~N} / \mathrm{m}^{3}$ & $\vdots$ \\
$8.75 \mathrm{e}+08 \mathrm{H} / \mathrm{m}^{2}$ \\
$2 \mathrm{e}+07 \mathrm{~Pa}$
\end{tabular} \\
\hline \multicolumn{3}{|l|}{$+x$} \\
\hline & & Cancel \\
\hline
\end{tabular}

a. Parameters of bonding model configuration

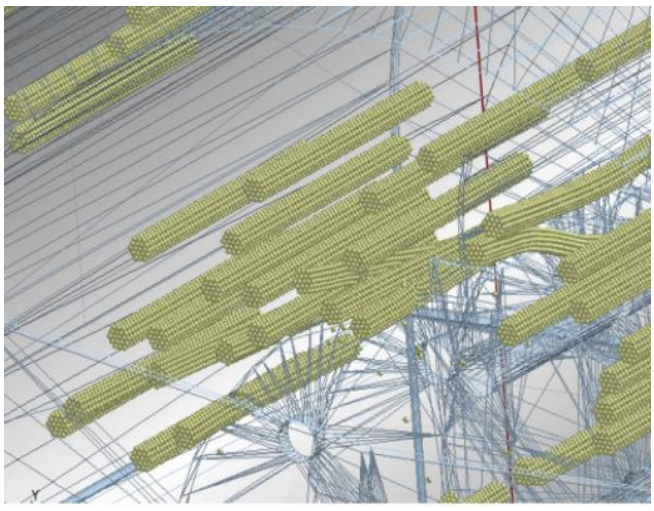

b. Particle replacement model

Figure 4 Setting of straw contact model

In general, when the time step is defined as $\Delta T=(0.05$ to 0.40) $\Delta T_{R}$, the stability and accuracy of the particle system can be ensured .In the case of intense particle movement, the calculation accuracy can be ensured when the time step is taken as $\Delta T=(0.05$ to 0.20$) \Delta T_{R}$. But in the simulation process, it is found that the straw particles will run into the pipe wall and appear "explosion" phenomenon when $\Delta T \geq 0.10 \Delta T_{R}$, so the time step is set as $\Delta T=0.05 \Delta T_{R}$, which is used to ensure the accuracy and stability of the simulation.

\section{Simulation experiment}

The main factors affecting the grinding effect of cucumber straw are hammer thickness, hammer number and arrangement, linear velocity at the end of hammers, gap between hammer and sieve and sieve hole diameter. In this study, through single factor simulation test, the effects of different hammers including thickness, number of hammers and gap between hammer and sieve on power consumption and grinding particle number are obtained. In the experiment, the position of the particle factory is set at the top of the grinding chamber, which is a square virtual body of
$250 \mathrm{~mm} \times 250 \mathrm{~mm}$. The generation time is $0-2 \mathrm{~s}$ and the total number of particles is 2000 .

\subsection{Simulation results}

The particle trajectory diagram in the grinding chamber can be obtained by simulation test as shown in Figure 5. Red, green and blue represent the particle velocity from high to low, respectively. It can also be verified from the figure with theoretical analysis that the density of straw particles is larger near the screen and the breaker plate. Figure 5 shows that the crushing process can be divided into three stages after the material enters the grinding chamber: at first, when the material enters the grinding chamber, its movement direction is different from that of the hammer. At this time, the straw is hit by hammers mostly, and the crushing effect of the hammers is obvious. In the second stage, under the combined action of scraper and hammers, the material is impacted back and forth between hammers and screen or breaker plate, smashed again, and forms a circulation layer. When the circulation layer is formed, the velocity of particles circulation layer tends to the linear velocity at the end of hammers, and because of the rapid operation and dense arrangement of hammers, it will form a similar wall structure, in which only a small number of particles collide with the screen or the breaker plate and rebound radially enter the central region of the rotor. Most of the particles move reciprocally between hammers and the screen or the breaker plate. Because of the shape characteristics of the grinding chamber, the impact grinding occurs above the grinding chamber. At this time, the grinding efficiency of the hammer is very low, and the grinding of the screen or the breaker plate is remarkable. In the final stage, owing to the negative pressure formed by the rotation of hammers, a small number of particles will enter the central region of the rotor and impact with hammers, while in the circulating material layer between hammers, the screen and the breaker plate, when the velocity of the particles decreases, it will accelerate again under the drive of hammers, and then continue to be crushed.

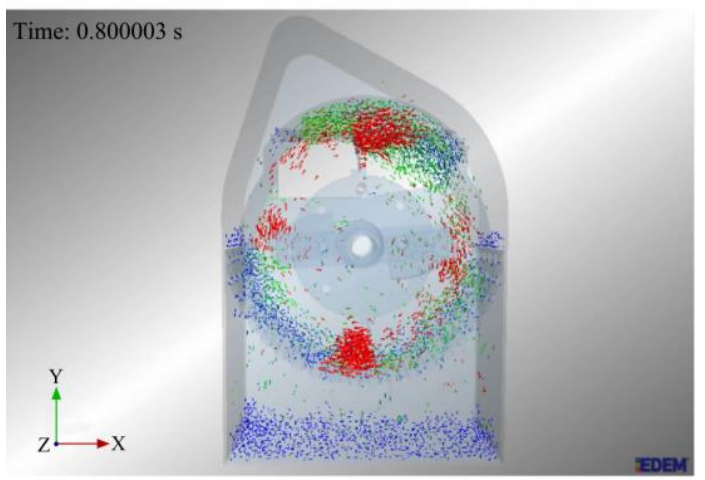

Figure 5 Particles flow field in a straw grinder

In EDEM simulation, the particle trajectory can be extracted by randomly selecting the moving particles in the grinding chamber, as shown in Figure 6. It shows that a particle is discharged directly through the screen without hammer impact from the upper part of the crushing chamber in Figure 6a. In Figure 6b, a random particle falls down under the action of gravity first from the upper part of the crushing chamber, and then is hit by the high-speed rotating hammer, which strikes the tooth plate, and then rebounds to the crushing chamber to complete the discharging through the screen. Most of the particles' motion is like in Figure $6 \mathrm{~b}$.

During the EDEM simulation process, according to the differential equation of particle motion, the maximum velocity, acceleration and total force of all particles at a certain time can also be obtained, as shown in Figure 7. 


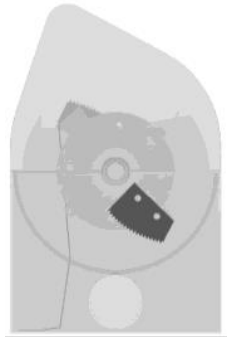

a. Direct discharge without impact

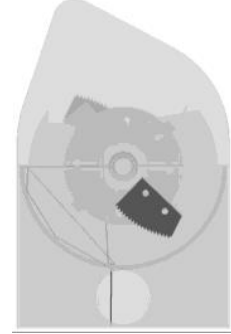

b. Discharge after repeated impact

Figure 6 Trajectory of a random particle

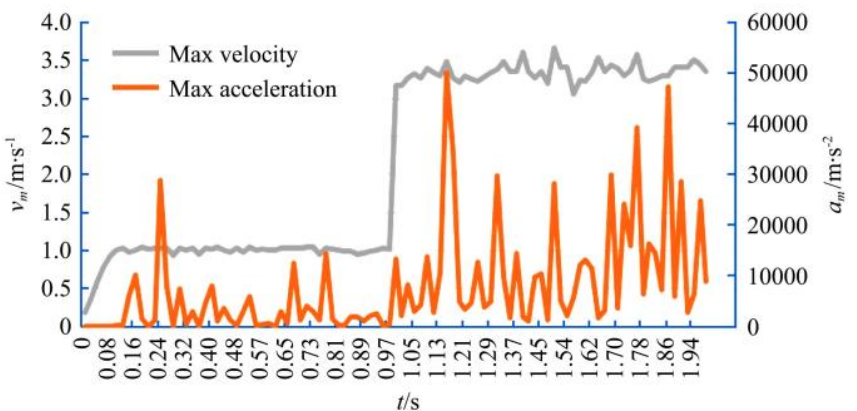

a. Maximum velocity and acceleration of all particles

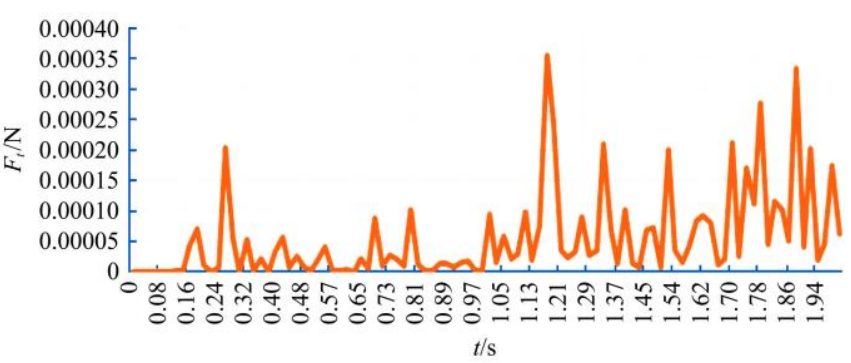

b. Total force

Figure 7 Motion information of all particles at a given time

By EDEM software, the velocity and angular velocity of a random particle at a certain time can also be obtained. Figure 8 shows the motion parameters of the specific particle in Figure $6 \mathrm{~b}$. It can be found that the particle appears at $1 \mathrm{~s}$, then is hit by a hammer and accelerates rapidly to obtain the maximum velocity. Then it impacts on the top gear plate. The velocity decreases in the process of particle flying, and rebounds to the screen mesh after the impact of the tooth plate as the velocity increases. The speed decreases in a straight line in the process of screening, and after passing the screen, it continues to fall to the bottom of the chamber, the speed of the process increases again because of gravity, and the final particle drops to the bottom at a speed of 0 .

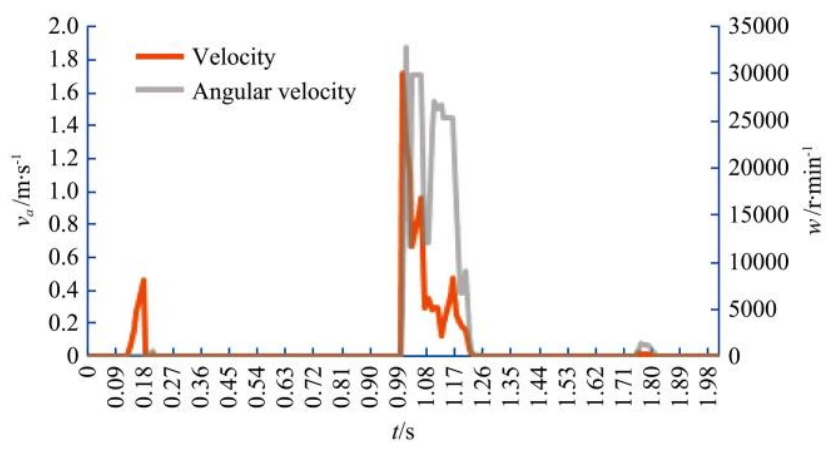

Figure 8 Motion parameters of the specific particle

\subsection{Simulation analysis}

5.2.1 Effect of different parameters of hammers on the number of crushed particles

The effects of the hammers number, hammers thickness $(h)$ and gap between hammers and sieves (1) on the number of crushed particles $(n)$ are shown in Figure 9.

Figure 9 shows that when straws enter the grinding chamber at $0-0.25 \mathrm{~s}$, its movement direction is different from that of hammers. At this time, most of the straws are hit by hammers, and hammer grinding is dominant. In this process, crushed straws partly diverge and partly form the granular circulation Layer. At 0.25-0.6 s, the grinding effect of hammers increases slowly first and then decreases. The grinding number of hammers reaches the minimum, and the grinding number of breaker plate rises rapidly, which has the main grinding effect. At 0.6-2.0 s, a stable granular circulation layer is formed, which is the third stage. The number of hammers crushed is basically stable at about 100 particles, and the number of breaker plate crushed is also stable at about 400 particles. It can be found that the first stage of grinding process is relatively short, in which hammers play a dominant role, and the third stage of grinding process is stable and durable. Breaker plate and hammers form a beating friction grinding together and breaker plate plays a dominant role.

The hammer has a significant effect on the number of crushed particles of the pulverizer. With the number of hammers increasing, the number of crushed particles smashed by hammers increases significantly, while the number of crushed particles smashed by breaker plate does not change significantly. The thickness of hammers has no obvious effect on the number of crushed particles of the pulverizer, and the number of crushed particles smashed by hammers increases slightly with the thickness of the hammer increasing. When the gap between hammers and screen increased, the number of crushed particles smashed by hammers slightly decreased, while the number of crushed particles smashed by the breaker plate did not change significantly.

5.2.2 Effect of different parameters on power consumption

The influence of the hammer number, hammer thickness $(h)$ and gap between hammers $(l)$ and sieves on the power consumption of straw $(P)$ in the crushing process is shown in Figure 10.

In the simulation process, the power consumption can be converted by real-time torque. With the number and thickness of hammers increasing, the power consumption of pulverizer tends to increase, and with the gap between hammers and sieves increasing, the power consumption of pulverizer tends to decrease. When the number of hammers is 16 , the maximum power consumption per ton is $312.70 \mathrm{~kW} \cdot \mathrm{h} / \mathrm{t}$ at $1.45 \mathrm{~s} ; 656.68 \mathrm{~kW} \cdot \mathrm{h} / \mathrm{t}$ at $1.45 \mathrm{~s}$ for 24 hammers; $110.00 \%$ for 32 hammers; $663.88 \mathrm{~kW} \cdot \mathrm{h} / \mathrm{t}$ at $1.41 \mathrm{~s}$ for the maximum power consumption per ton, $112.31 \%$ for 16 hammers. When the thickness of hammers is $4 \mathrm{~mm}$, the maximum power consumption per ton of material is $312.70 \mathrm{~kW} \cdot \mathrm{h} / \mathrm{t}$; when the thickness of hammers is $5 \mathrm{~mm}$ and $6 \mathrm{~mm}$, the maximum power consumption per ton of material is 375.24 and $531.60 \mathrm{~kW} \cdot \mathrm{h} / \mathrm{t}$ respectively, which increases by $20 \%$ and $70 \%$ respectively. When the gap between hammers and screen is $8 \mathrm{~mm}$, the maximum power consumption per ton of material is $312.70 \mathrm{~kW} \cdot \mathrm{h} / \mathrm{t}$; when the gap between hammers and screen is $12 \mathrm{~mm}, 16 \mathrm{~mm}$ and $20 \mathrm{~mm}$, the maximum power consumption per ton of material is $281.43 \mathrm{~kW} \cdot \mathrm{h} / \mathrm{t}, 259.78 \mathrm{~kW} \cdot \mathrm{h} / \mathrm{t}$ and $173.19 \mathrm{~kW} \cdot \mathrm{h} / \mathrm{t}$, respectively, which reduces by $10.00 \%, 16.92 \%$ and $44.61 \%$ respectively. The reason is that when the thickness and number of hammers increase, the overall mass of the rotor increases, and the total power consumption increases with the number of crushed particles increasing as shown in Figure 9a. With the gap between hammers and the screen increasing, the thickness of the circulation layer increases. As shown in Figure 9c, the number of particles smashed by hammers decreases, thus the power consumption decreases. 


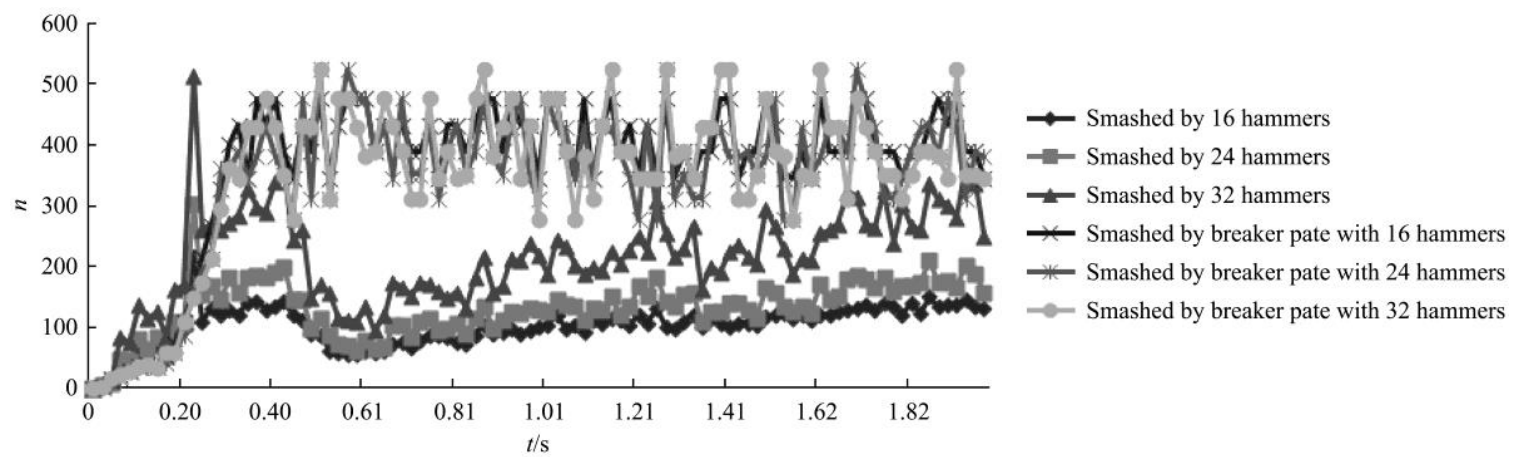

a. Influence of the number of hammers on the number of grinding particles in the grinding chamber

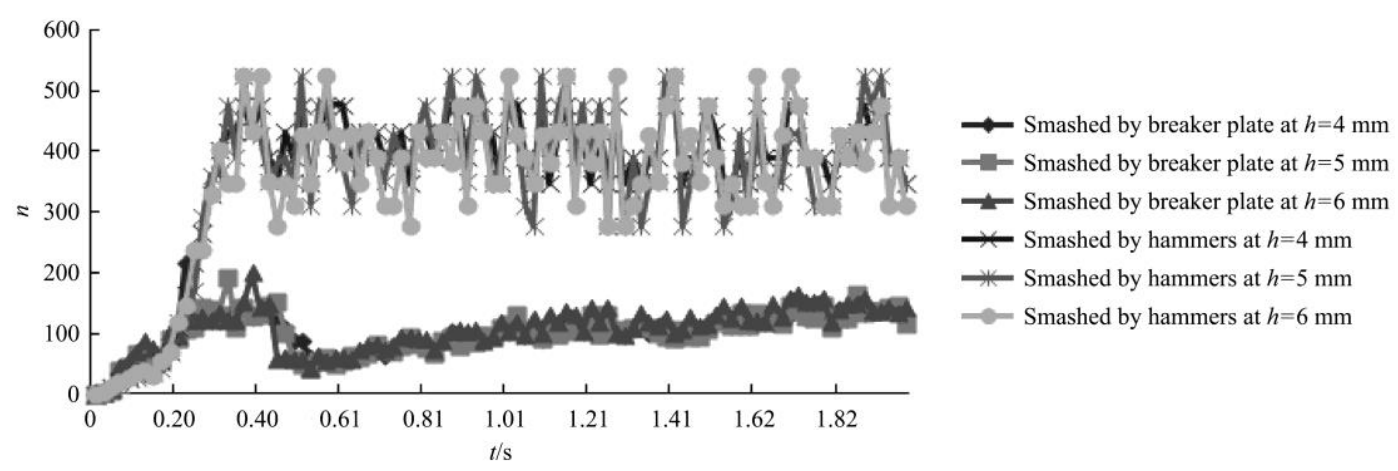

b. Influence of hammer thickness on the number of grinding particles in the grinding chamber

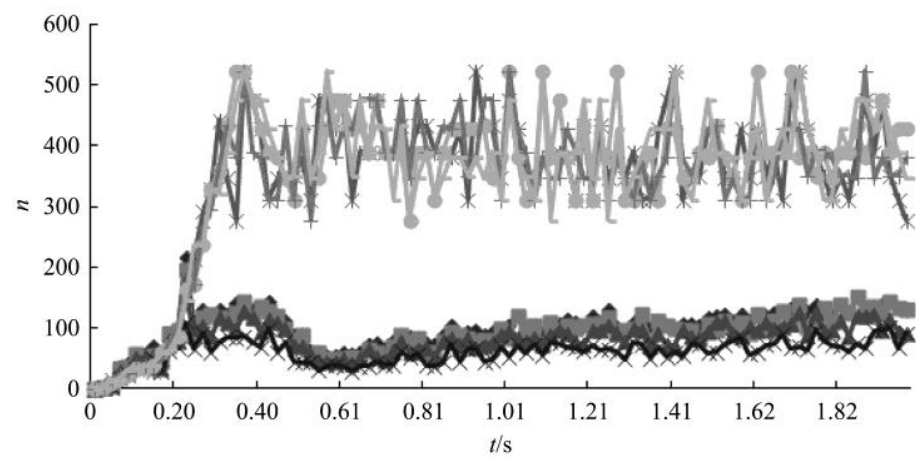

$\multimap$ Smashed by hammers at $l=8 \mathrm{~mm}$

- - Smashed by hammers at $l=12 \mathrm{~mm}$

- Smashed by hammers at $l=16 \mathrm{~mm}$

* Smashed by hammers at $l=20 \mathrm{~mm}$

* Smashed by breaker plate at $l=8 \mathrm{~mm}$

$\multimap$ Smashed by breaker plate at $l=12 \mathrm{~mm}$

- Smashed by breaker plate at $l=16 \mathrm{~mm}$

- Smashed by breaker plate at $l=20 \mathrm{~mm}$

c. Influence of hammer-sieve gap on the number of grinding particles in the grinding chamber

Figure 9 Influence of different parameters on the number of grinding particles

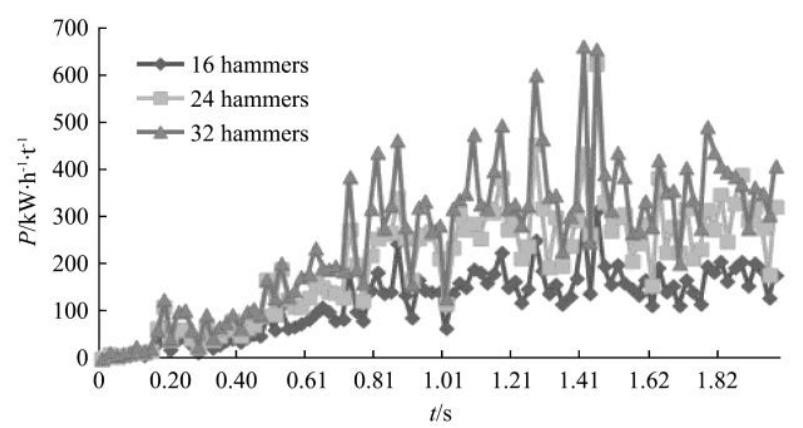

a. Influence of the number of hammers on power consumption

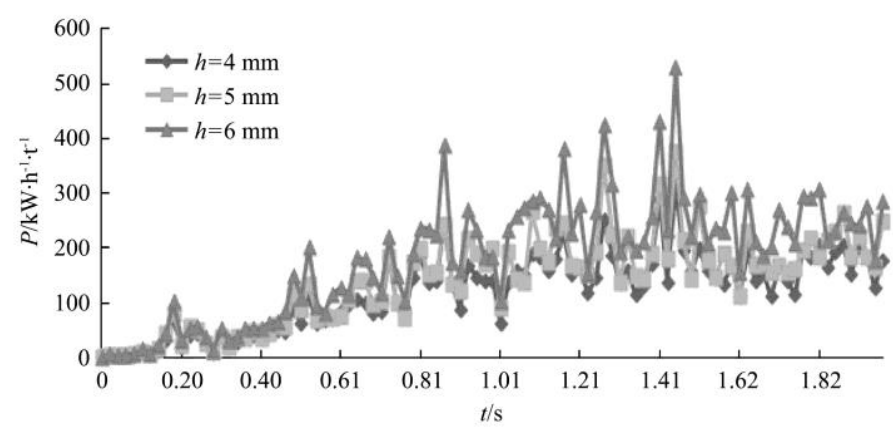

b. Influence of hammers thickness on power consumption

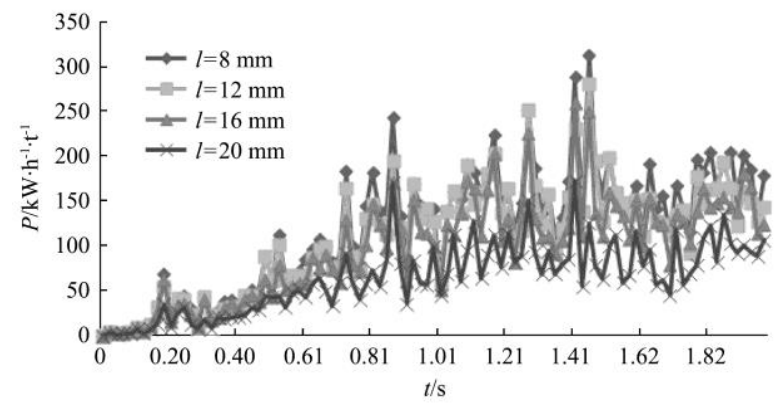

c. Influence of hammer-sieve gap on power consumption

Figure 10 Influence of different parameters on power consumption 


\section{Crushing test of cucumber straw}

\subsection{Materials and equipment}

The test cucumber straw was collected from the mature cucumber of the greenhouse in the Ruijingyuan Science and Technology Demonstration Park in Zhenjiang City. The variety was Jasper No.2. The planting date was July 16, 2015, and the harvest date was November 23. The cucumber straw was naturally dried and then pulverized, as shown in Figure 11. Pay attention to the removal of plastic film, winding rope, cucumber and stone before feeding.

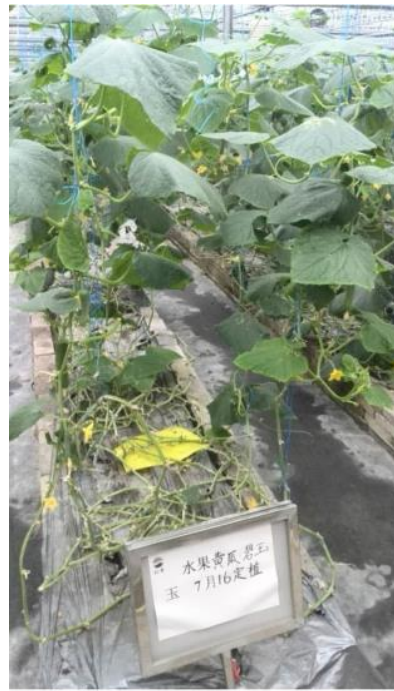

a. Ripe cucumber straw

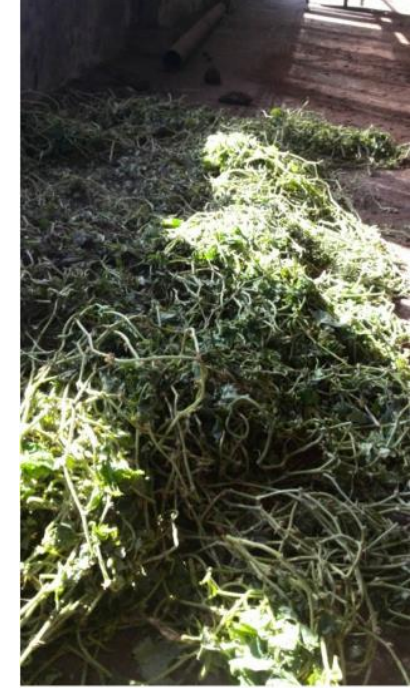

b. Cucumber straw after harvest
Figure 11 Cucumber straw in the test

The test equipment mainly includes 3FC-500 multi-functional straw grinder as shown in Figure 12, three-phase combined electric meter, XK3150 high-precision electronic scale, stopwatch and ZS30R intelligent noise meter. The 3FC-500 multi-functional straw grinder can pulverize all kinds of dry and wet straws, and the grinder has feed inlets both on the top and side, which can realize tangential, radial and axial feeding. The side feed port is equipped with a fixed knife and a movable knife, which can cooperate with the pre-cutting to attain the purpose of cutting first and then smash. The spindle speed of the straw grinder is $1500 \mathrm{r} / \mathrm{min}$, the rotor diameter is $0.5 \mathrm{~m}$, and the end line speed of hammers is $39.26 \mathrm{~m} / \mathrm{s}$. Idle a few minutes at the beginning of the experiment. Start the manual feeding after the stable rotation. Continue to run for a few minutes after stopping feeding, so that the material is completely pulverized and then shut down. Record the opening and closing time and the meter reading at this moment.

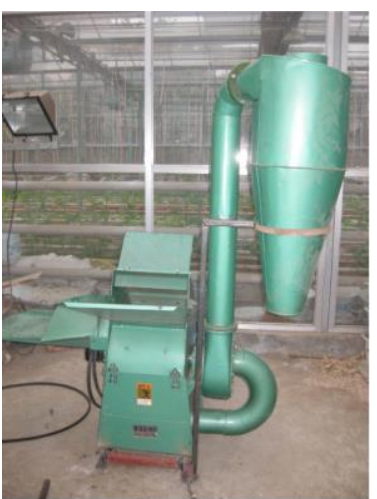

a. Straw grinder

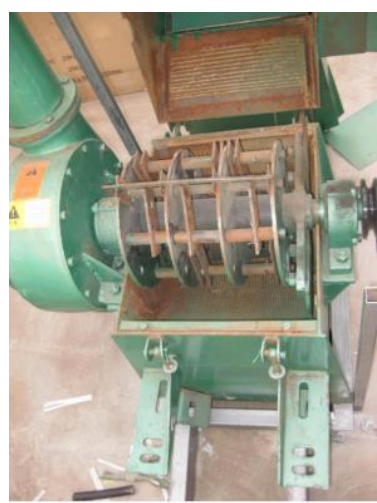

b. Structure of crushing chamber
Figure 12 3FC-500 straw grinder
The fan discharge port and the surrounding straw scraps were collected, and the quality of the cucumber straw before and after crushing was weighed. Change the number, the thickness and the length of the hammers (change the gap between hammers and screen) to compare and analyze the influence of various factors on the power consumption.

\subsection{Test results}

When the sieve hole diameter was $4 \mathrm{~mm}$, the cucumber straw with a water content of $18 \%$ was crushed at different numbers of hammers $(N)$, hammer thicknesses $(h)$ and hammer screen gaps $(l)$. The results are shown in Table 5, where $P_{s}$ is the maximum power consumption per ton of material in the simulation; $P_{t}$ is the power consumption per ton of material in the test; $\varepsilon$ is the error between the simulation and the test.

Table 5 Influence of the parameters of the hammers on the crushing performance

\begin{tabular}{cccc}
\hline Parameters & $P_{s} / \mathrm{kW} \cdot \mathrm{h} \cdot \mathrm{t}^{-1}$ & $P_{t} / \mathrm{kW} \cdot \mathrm{h} \cdot \mathrm{t}^{-1}$ & $\varepsilon / \%$ \\
\hline$N=16$ & 312.70 & 344.16 & 10.06 \\
$N=24$ & 656.68 & 339.15 & -48.35 \\
$N=32$ & 663.88 & 683.52 & 2.96 \\
$h=4 \mathrm{~mm}$ & 312.70 & 344.16 & 10.06 \\
$h=5 \mathrm{~mm}$ & 375.24 & 373.15 & -0.56 \\
$h=6 \mathrm{~mm}$ & 531.60 & 448.62 & -15.61 \\
$l=8 \mathrm{~mm}$ & 312.70 & 344.16 & 10.06 \\
$l=12 \mathrm{~mm}$ & 281.43 & 322.70 & 14.66 \\
$l=16 \mathrm{~mm}$ & 259.78 & 293.37 & 12.93 \\
$l=20 \mathrm{~mm}$ & 173.19 & 354.56 & 104.72 \\
\hline
\end{tabular}

\subsection{Analysis of the test results}

In the test, the pulverizing power consumption increased with the number of hammers increasing, which is consistent with the simulation. As the number of hammers increases, the mass of the rotor increases, so that the no-load power becomes larger, and the effective power is relatively reduced. In addition, the number of hits on the material will increase, which results in a finer particle size, causing over-grinding and greater power consumption. Therefore, there is a tendency for the number of hammers to decrease in grinder designs. Obviously, the less number of hammers is not better, and too few hammers will reduce the smash efficiency and output. There is an optimum hammer density, and it is known from the test that when the number of hammers is 16 , it has a good smash efficiency. Because the power consumption per ton of material in the test is an average power consumption of the pulverization process, there is a large error with the maximum power consumption per ton of material in simulation.

As the thickness of the hammer increase, the crushing power consumption increase, and the crushing effect become worse. This trend is consistent with the simulated results. The reason is that as the thickness increases, the impact force and the hitting area increase, and it is easy to stir up the straw, so that the straw rotates at the same speed with hammers to form a material circulation layer. At this time, the material is struck by the high-speed impact of the hammer to sharpen the material and the screen, the corners of the hammer, and the tooth plate. According to the test, the pulverization power consumption is low, and the pulverization efficiency is high with the hammer of $4 \mathrm{~mm}$ thickness.

As the gap between hammers and screen increases, the power consumption of the grinder decreases first and then increases, which is slightly different from the trend that has been reduced in the simulation. The reason is that as the gap increases, the speed 
of large particles near the screen becomes slower, which is good for sieving. It improves the screening efficiency, and reduces the power consumption of the pulverization. However, when the gap is increased to $20 \mathrm{~mm}$, the straw particles in the test will clog the sieve holes and will not be screened smoothly, resulting in an increase in power consumption per ton of material, and the problem of clogging is not considered in the simulation, causing a difference in power consumption with the test. Therefore, according to the test, when the gap between the hammers and sieve is selected to be $16 \mathrm{~mm}$, the power consumption per ton of material is the smallest and the pulverization efficiency is the highest.

\section{Conclusions}

The grinding process of cucumber straw in the hammer mill was studied by force analysis, kinematics analysis, EDEM software simulation and experiment. The following results are obtained:

According to the differential equation of the movement of straw particles on the hammer, the particles circulation layer is formed in the grinding chamber. Close to the sieve screen outside, the big particles are easy to be blocked, and near hammers inside, the small particles are easy to be smashed. The screening efficiency can be improved by increasing the initial feeding speed and reducing the speed of rotor.

EDEM software was used to simulate and verify that the distribution of particles density along the rotation radius of straw particles in theoretical analysis was from small to large, and the maximum density was near the top of screen or breaker plate. The screening efficiency could be improved by widening screen.

At $0-0.25 \mathrm{~s}$, hammer smashing plays a dominant role; at $0.25-0.6 \mathrm{~s}$, the particles circulation layer gradually forms in the grinding chamber, and the number of crushed particles in the breaker plate increases rapidly, which becomes the dominant role in particle smashing; at 0.6-2.0 s, the crushed particles by hammers are about 100 , while the crushed particles by the breaker plate are about 400

With the number and thickness of hammers increasing, the power consumption of grinder increases; with the increase of the gap between hammers and sieves, the power consumption of grinder decreases first and then increases.

By comparing the numerical simulation results with the test results, the trend of power consumption is basically the same, which proves the correctness of the simulation model. Considering the number of crushing particles and the power consumption, it is suggested that the optimum parameters should be the number of hammers 16 , the thickness of hammers $4 \mathrm{~mm}$, and the gap between hammers and sieves $16 \mathrm{~mm}$.

\section{Acknowledgements}

This work was supported by the National Key Technologies R\&D Program of China (No.2014BAD08B04) and the National Natural Science Fund of China (No.51175230, No.51475212) and the Funding for Key R \& D Programs in Jiangsu Province (BE2018321).

\section{[References]}

[1] Xu Y F, Li P P, Zhang X L. Design of universal straw cutting mill. Applied Mechanics and Materials, 2011; 43: 283-287.

[2] Xu Y F. Study on the mechanism and performance of multi-stage cyclic pulverization of cucumber straw. Zhenjiang: Jiangsu University, 2018. (in Chinese)
[3] Wang T L. Development and change of cucumber production in China. Northwest Horticulture, 2015; 25: 4-6. (in Chinese)

[4] Guo S R, Sun J, Shu S, Lu X M, Tian J, Wang J W. Analysis of general situation, characteristics, existing problems and development trend of protected horticulture in China. China Vegetables, 2012; 18: 1-14. (in Chinese)

[5] He F, Qi F, Bao S S, Ding X M, Wei X M, Li Z H. Current problems and suggestions of protected horticulture in China. Northern Horticulture, 2010; 34(15): 29-32. (in Chinese)

[6] He C X, Yu X C. Development trend and prospect of major vegetable production in the world. Vegetables, 2012; 12: 1-6. (in Chinese)

[7] Xu Y F, Zhang X L, Sun X J, Chen C, Guo Q, Li P P. Design of the cutting test-bed and control system of vine straw. In: The Annual Conference of ASABE, 2014

[8] Zhang X L, Sun X J, Xu Y F, Li P P, Guo Q, Zhang S Q Mechanical characteristics and microstructure of cucumber vine straw. Journal of Agricultural Mechanization Research, 2014; 36: 156-159. (in Chinese)

[9] Xu Y F, Zhang X L, Sun X J, Wang J Z, Liu J Z, Li Z G, et al. Tensile mechanical properties of greenhouse cucumber cane. Int J Agric \& Biol Eng, 2016; 9(5): 1-8.

[10] Chen L D, Yang X W, Chen W, Yang X W. Effects of water-fertilizer coupling with straw returning on yield and quality of rice. Journal of Drainage and Irrigation Machinery Engineering, 2018; 36: 1152-1156. (in Chinese)

[11] Li Y M, Chandio F A, Ma Z, Lakhiar I A, Sahito A R, Ahmad F, et al Mechanical strength of wheat grain varieties influenced by moisture content and loading rate. Int J Agric \& Biol Eng, 2018; 11(4): 52-57.

[12] Ngamnikom P, Songsermpong S. The effects of freeze, dry, and wet grinding processes on rice flour properties and their energy consumption. Journal of Food Engineering, 2011; 104: 632-638.

[13] Bitra V S P, Womac A R, Cannayen I, Miu P I, Yang Y T, Sokhansanj S Comminution energy consumption of biomass in knife mill and its particle size characterization. Reno: ASABE, 2009.

[14] Guo Q, Zhang X L, Xu Y F, Li P P, Chen C, Wu S. Design and experiment of cutting blade for cane straw. Transactions of the CSAE, 2014; 30: 47-53. (in Chinese)

[15] Zhang L, Ruan J L. The analysis of influence factor and research stayus of hammer mill. Packaging and Food Machinery, 2013: 6: 55-57.

[16] Dey S K, Dey S, Das A. Comminution features in an impact hammer mill. Powder Technology, 2013; 235: 914-920.

[17] Chen Y X, Chen L, Huang C, Lu Y, Wang C. A dynamic tire model based on HPSO-SVM. Int J Agric \& Biol Eng, 2019; 12(2): 36-41.

[18] Tang Z, Li Y M, Cheng C. Development of multi-functional combine harvester with grain harvesting and straw baling. Spanish Journal of Agricultural Research, 2017; 15: e0202.

[19] McCarthy J J, Khakhar D V, Ottino J M. Computational studies of granular mixing. Powder Technology, 2000; 109: 72-82.

[20] Sakaguchi E, Suzuki M, Favier J F, Kawakami S. Numerical simulation of the shaking separation of paddy and brown rice using the discrete element method. J. Agric Eng Res, 2001; 79: 307-315.

[21] Wu S, Li P P, Zhang X L, Xu Y F, Liu J Z, Wang J Z. Vertical spiral mixing mechanism of tomato straw particles based on discrete element method. Journal of Drainage and Irrigation Machinery Engineering, 2018 36: 719-724. (in Chinese)

[22] Zhang Y N, Chen F P, Zhang Y N, Zhang Y X, Du X Z. Experimental investigations of interactions between a laser-induced cavitation bubble and a spherical particle. Experimental Thermal \& Fluid Science, 2018; 98: 645-661.

[23] Zhang Y N, Zhang Y N, Qian Z, Ji B, Wu Y L. A review of microscopic interactions between cavitation bubbles and particles in silt-laden flow. Renewable \& Sustainable Energy Reviews, 2016; 56: 303-318.

[24] Cao L, Li C. Numerical simulation on air-flow field in the milling chamber of hammer mill. International Conference on Mechanic Automation \& Control Engineering. IEEE, 2011; pp. 476-479.

[25] Hu G M. Discrete element method analysis and simulation of particle systems: industrial application of discrete element method and introduction of EDEM software. Wuhan: Wuhan University of Technology Press, 2010. (in Chinese)

[26] Shi Y F, Zhang X L, Xu Y F, Cui S J. Influence of feeding method on feed quantity of screw feeder. Journal of Drainage and Irrigation Machinery Engineering, 2019; 37: 341-345. (in Chinese) 
[27] Wu S. Analysis and experiment of vertical screw mixing method for tomato straw and fermentation strains. Zhenjiang: Jiangsu University, 2016. (in Chinese)

[28] Guo Q, Zhang X L, Xu Y F, Li P P, Chen C, Xie H W. EDEM-based simulation and experiment on tomato cane straw cutting performance. Journal of Drainage and Irrigation Machinery Engineering, 2018; 36: 1017-1022. (in Chinese)

[29] Li H C, Li Y M, Gao F, Zhao Z, Xu L Z. CFD-DEM simulation of material motion in air-and-screen cleaning device. Computers \& Electronics in Agriculture, 2012; 88: 111-119.

[30] Markauskas D, Kruggelemden H, Sivanesapillai R, Steeb H. Comparison of mesh-based and particle-based CFD coupling with DEM. Powder Technology, 2016; 305: 78-88.

[31] Ebrahimi M, Crapper M, Ooi J Y. Numerical and experimental study of horizontal pneumatic transportation of spherical and low-aspect-ratio cylindrical particles. Powder Technology, 2016; 293: 48-59. 